Check for updates

Cite this: Chem. Sci., 2018, 9, 6969

๑ All publication charges for this article have been paid for by the Royal Society of Chemistry

Received 20th April 2018

Accepted 12th July 2018

DOI: $10.1039 / \mathrm{c} 8 \mathrm{sc} 01804 a$

rsc.li/chemical-science

\section{Bifunctional iminophosphorane catalysed enantioselective sulfa-Michael addition of alkyl thiols to alkenyl benzimidazoles $\uparrow$}

\author{
Michele Formica, (ID $\ddagger^{a}$ Geoffroy Sorin, (ID $\ddagger^{a b}$ Alistair J. M. Farley, Jesús Díaz, (D) \\ Robert S. Paton (iD *d and Darren J. Dixon (iD *a
}

The first enantioselective sulfa-Michael addition of alkyl thiols to alkenyl benzimidazoles, enabled by a bifunctional iminophosphorane (BIMP) organocatalyst, is described. The iminophosphorane moiety of the catalyst provides the required basicity to deprotonate the thiol nucleophile while the chiral scaffold and $\mathrm{H}$-bond donor control facial selectivity. The reaction is broad in scope with respect to the thiol and benzimidazole reaction partners with the reaction proceeding in up to $98 \%$ yield and $96: 4$ er.
$\mathrm{N}$-Containing heterocycles are ubiquitous motifs in both biologically active molecules and natural products. Their functionalization, especially when performed in an enantioselective manner, is therefore of particular interest in the field of organic synthesis. Alkenyl azaarenes have been used extensively as synthetic precursors for the functionalization of N-containing heterocycles. ${ }^{1}$ The electron deficiency of the aromatic ring, part-activates the conjugated alkene towards Michael-type additions, ${ }^{2}$ allowing for the rapid generation of molecular complexity. Most recently, the groups of Harutyunyan, Terada and Meng reported elegant, highly enantioselective Michael additions to alkenyl $\mathrm{N}$-heterocycles employing organocuprates, ${ }^{3}$ pyrazoles ${ }^{4}$ and $\mathrm{B}_{2}(\text { pin })_{2}{ }^{5}$ respectively.

Our research has focused on developing enantioselective methods utilizing novel bifunctional iminophosphorane (BIMP) organocatalysts, ${ }^{6}$ which combine a chiral H-bond donor scaffold ${ }^{7}$ with an organo-superbase. ${ }^{8}$ More specifically, BIMP catalysis has been employed in the enantioselective addition of thiols $^{9,10}$ to unactivated esters. ${ }^{6 c, g}$ This encouraged us to consider replacing the enoate electrophile with isoelectronic alkenyl benzimidazoles in order to access complex, chiral druglike scaffolds with perfect atom economy and potential

\footnotetext{
${ }^{a}$ Department of Chemistry, Chemistry Research Laboratory, University of Oxford, Mansfield Road, Oxford OX1 3TA,UK. E-mail: darren.dixon@chem.ox.ac.uk

${ }^{b}$ Faculté des Sciences Pharmaceutiques et Biologiques, Unité CNRS UMR 8638 COMETE, Paris Descartes University, Sorbonne Paris Cité, 4 Avenue de l'Observatoire, 75270 Paris Cedex 06, France

'Departamento de Química Orgánica, Universidad de Extremadura, Avda. Universidad, s/n, 10003 Cáceres, Spain

${ }^{d}$ Department of Chemistry, Colorado State University, Fort Collins, Colorado 80523, USA

$\dagger$ Electronic supplementary information (ESI) available. CCDC 1833189. For ESI and crystallographic data in CIF or other electronic format see DOI: 10.1039/c8sc01804a

$\ddagger$ These authors contributed equally.
}

applications to medicinal chemistry (Fig. 1). ${ }^{11}$ To the best of our knowledge, there have been no reports to date of the enantioselective base catalysed Michael additions to alkenyl benzimidazoles ${ }^{12}$ and herein we wish to report our work leading to the first example, under BIMP catalysis.

We chose the readily prepared $^{4}(E)$-2-propenyl-1-tosylbenzimidazole $\mathbf{1}$ and commercially available 1-propanethiol as model coupling partners to investigate reactivity and selectivity with a selection of bifunctional Brønsted base/H-bond donor catalysts using 3 eq. of thiol at $0.5 \mathrm{M}$ concentration in THF at $22{ }^{\circ} \mathrm{C}$ for 24 hours (Fig. 2, Table 1). Quinidine derived catalyst $\mathbf{A}$ (entry 1 ) only provided 2 in $12 \%$ yield and a negligible $53: 47$ er. We therefore chose to investigate the more basic and more active BIMP catalysts in this reaction and were very pleased to find that known BIMP catalyst $\mathbf{B}^{6 a}$ bearing one stereocenter provided desired product 2 in $80 \%$ yield and $83: 17$ er (entry 2). With significant catalyst-enabled reactivity and stereocontrol identified we then proceeded to investigate second generation catalyst $\mathbf{C}^{6 g}$ which provided 2 in improved yield and er at $92 \%$ and $86: 14$ respectively (entry 3 ). Shifting the thiourea moiety further away from the iminophosphorane $(\mathbf{D}-\mathbf{E})^{6 \boldsymbol{d}}$ showed no improvement in er over $\mathbf{B}$ (entries 4 and 5). We therefore focused on exploring catalysts built around the same chiral scaffold as C. Catalyst $\mathbf{F}^{6 g}$ bearing ${ }^{t}$ Bu groups at both stereocenters in the $(S, S)$ configuration afforded 2 in $90 \%$ yield and $90: 10$ er (entry 6). Interestingly, a control reaction without any catalyst was found to go to completion (entry 7), indicating that an uncatalysed background reaction ${ }^{13}$ pathway was leading to an erosion in the enantiomeric ratio of the product. To suppress this background reactivity, the reaction was diluted to $[0.06 \mathrm{M}]$, cooled to $0{ }^{\circ} \mathrm{C}$ and only 1.2 eq. of thiol were used. The new set of conditions, combined with a solvent switch from THF to $\mathrm{Et}_{2} \mathrm{O}$, provided 2 in 93\% yield and $94: 6$ er using catalyst $\mathbf{F}$ (entry 8). Surprisingly a further decrease of the temperature to $-40{ }^{\circ} \mathrm{C}$ led 

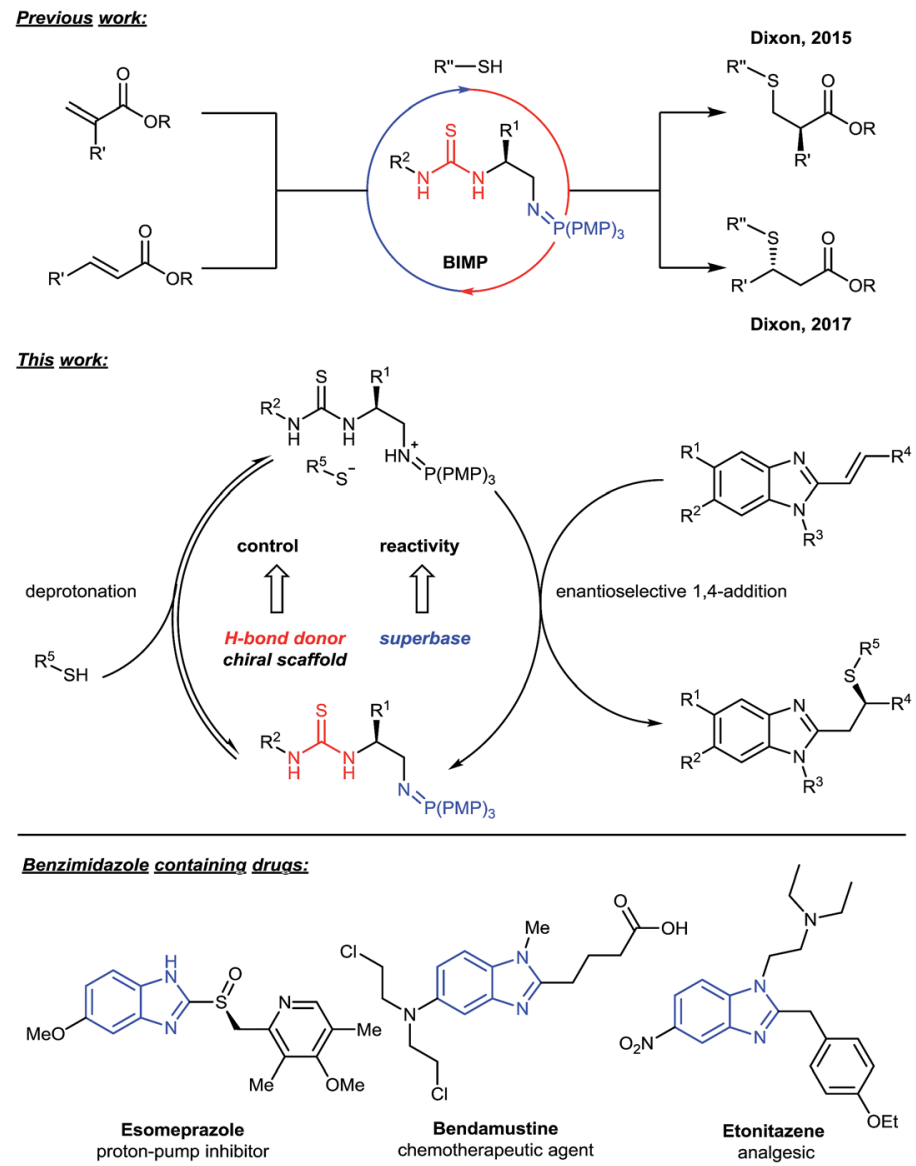

Fig. 1 (Top) Previous BIMP catalysed sulfa-Michael additions to unactivated esters and current application to conjugated alkenyl benzimidazoles with a plausible catalytic cycle. (Bottom) Selected relevant benzimidazole containing drugs. PMP = para-methoxyphenyl.<smiles>C=CC1CC2CCC1N2C(NC(=S)Nc1cc(C(F)(F)F)cc(C(F)(F)F)c1)c1ccnc2ccc(OC)cc12</smiles><smiles>CC(C)(C)C(CN=CN)NC(=S)Nc1cc(C(F)(F)F)cc(C(F)(F)F)c1</smiles>

B<smiles>CC(C)(C)C(NC(=S)NC(CN=C=O)c1ccccc1)C(=O)NC(c1ccccc1)c1ccccc1</smiles><smiles>CC(NC(=S)Nc1cc(C(F)(F)F)cc(C(F)(F)F)c1)C(=O)NC(CN=[Po])C(C)(C)C</smiles><smiles>CC(C)(C)C(CN=[P+]=O)NC(=S)NC(C(=O)Nc1ccccc1)C(C)(C)C</smiles><smiles>CC(C)(C)C(CN=CPN)NC(=S)NC(C(=O)NC(c1ccccc1)c1ccccc1)C(C)(C)C</smiles>

G

Fig. 2 Selected BIMP catalysts investigated for the optimization of the sulfa-Michael addition. PMP = para-methoxyphenyl.

to an erosion of the enantiomeric ratio (entry 9). To further boost the enantiomeric ratio, diastereoisomeric catalyst $\mathbf{G}^{\mathbf{6 g}}$ was screened. Pleasingly, catalyst G outperformed corresponding

diastereomer $\mathbf{F}$ affording the desired product in $98 \%$ yield and 95 : 5 er (entry 10).

With optimal conditions established, we proceeded to explore the scope and limitations of this transformation (Scheme 1). Initially the steric and electronic properties of the thiol nucleophile were varied. Higher order linear, branched and cyclic alkyl substituents on the thiol all provided the corresponding Michael adducts (3-5) with high yields and enantioselectivities. The introduction of a phenyl ring was well tolerated providing $\mathbf{6}$ in outstanding yield and good er. Appending a silyl group to the thiol nucleophile showed no detrimental effect providing 7 in excellent yield and er. Benzyl thiols provided corresponding Michael adducts 8-10 in high yields in all cases and good enantioselectivity, albeit slightly diminished when compared to simpler alkyl thiols. ${ }^{15,16}$

Having investigated the thiol component, we then focused on substituent effects on the benzimidazole core (Scheme 2). Variations to the phenyl backbone did not affect reactivity, disubstitution at C5 and C6 with methyl groups afforded corresponding adduct 11 in 81\% yield and 86 : 14 er. Alternating monosubstitution between C5 and C6 did not have a large effect, with bromine containing substrates affording the corresponding Michael adducts $(\mathbf{1 2}, \mathbf{1 3})$ in greater than $75 \%$ yield and $86: 14$ er allowing for potential further functionalization at both positions. ${ }^{17}$ 
Table 1 Reaction optimization. Full optimization data available in the ESI

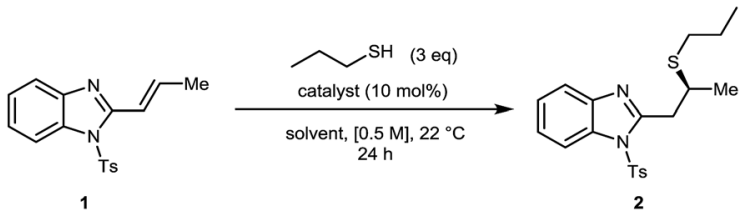

\begin{tabular}{lllll}
\hline Entry & Catalyst & Solvent & Yield $^{a}(\%)$ & $\mathrm{er}^{b}$ \\
\hline 1 (ref. 14) & A & THF & 12 & $53: 47$ \\
2 & B & THF & 80 & $83: 17$ \\
$3^{c}$ & C & THF & 92 & $86: 14$ \\
4 & D & THF & 83 & $66: 34$ \\
5 & $\mathbf{E}$ & THF & 95 & $83: 17$ \\
6 & F & THF & 90 & $90: 10$ \\
$7^{d}$ & None & THF & 95 & $50: 50$ \\
$8^{e}$ & F & $\mathrm{Et}_{2} \mathrm{O}$ & 93 & $94: 6$ \\
$9^{f}$ & $\mathbf{F}$ & $\mathrm{Et}_{2} \mathrm{O}$ & 88 & $82: 18$ \\
$\mathbf{1 0}^{e}$ & $\mathbf{G}$ & $\mathbf{E t}_{\mathbf{2}} \mathbf{O}$ & $\mathbf{9 8}$ & $\mathbf{9 5}: \mathbf{5}$
\end{tabular}

${ }^{a}$ Isolated yield. ${ }^{b}$ Determined by HPLC analysis on a chiral stationary phase. ${ }^{c}$ Reaction carried out at $0.25 \mathrm{M}$ concentration. ${ }^{d}$ Reaction carried out over $72 \mathrm{~h} .{ }^{e}$ Reaction carried out at $0{ }^{\circ} \mathrm{C}$, using 1.2 eq. of thiol and $0.06 \mathrm{M}$ concentration. ${ }^{f}$ Reaction carried out at $-40{ }^{\circ} \mathrm{C}$, using 1.2 eq. of thiol and $0.06 \mathrm{M}$ concentration.
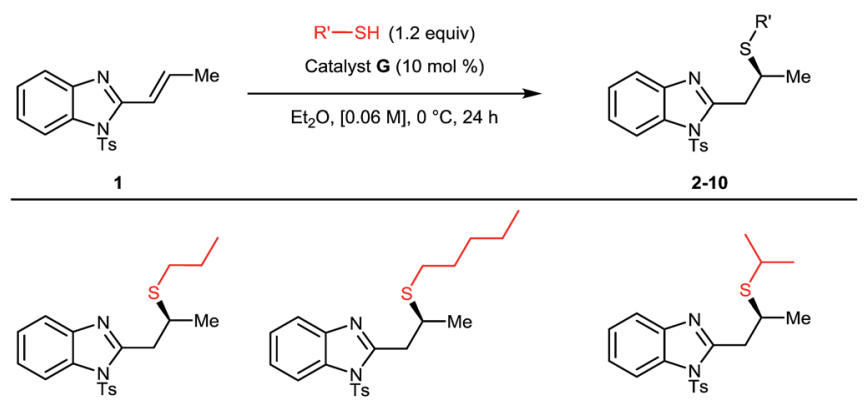

2, 98\% yield, $95: 5$ er

3, $78 \%$ yield, $95: 5$ er

$4^{\text {a }}, 78 \%$ yield, $94: 6$ er
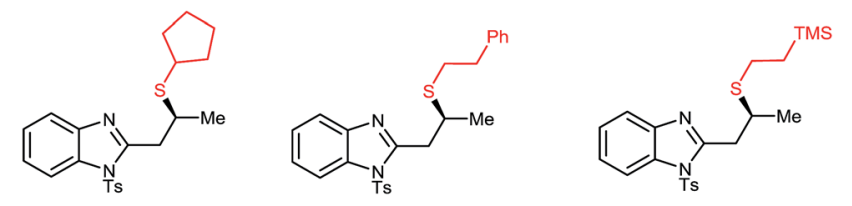

$5^{\text {a }}, 91 \%$ yield, $95: 5$ er

6, $93 \%$ yield, $92.5: 7.5 \mathrm{er}$

$7,94 \%$ yield, $96: 4$ er

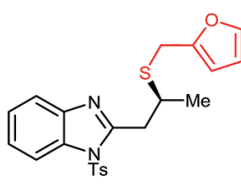

8, 91\% yield, $89: 11$ er

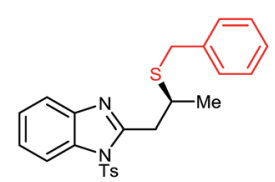

9; $89 \%$ yield, $89: 11$ er

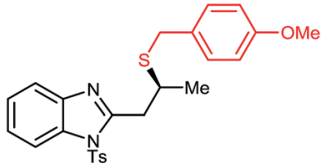

10; $98 \%$ yield, $92: 8$ er

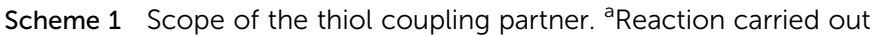
at $22{ }^{\circ} \mathrm{C}$.

We were pleased to find that the high enantioselectivity of the reaction was largely maintained when the nitrogen protecting group was changed from $N$-tosyl to $N$-Cbz (14) or $N$-Boc

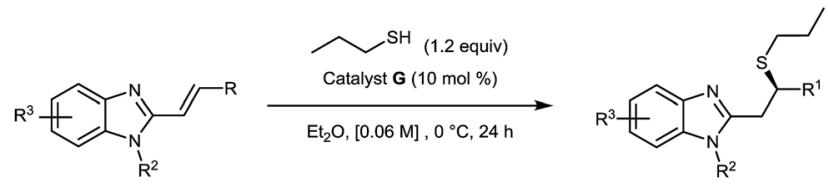<smiles></smiles>

$11,81 \%$ yield, $86: 14$ er<smiles>CCCS[C@@H](C)Cc1nc2ccccc2[nH]1</smiles>

$14^{\mathrm{a}, \mathrm{d}}, 61 \%$ yield, $92.5: 7.5 \mathrm{er}$<smiles>CCCS[C@@H](C[15N])Cc1nc2ccc(Br)cc2n1S</smiles>

12, $77 \%$ yield, $86: 14$ er<smiles>CCCS[C@@H](C)Cc1nc2ccccc2[nH]1</smiles>

$15^{\mathrm{a}, \mathrm{d}}, 98 \%$ yield, 91.5:8.5 er<smiles>CCCS[C@@H](C)Cc1nc2cc(Br)ccc2[nH]1</smiles>

$13,81 \%$ yield, $84: 16$ er

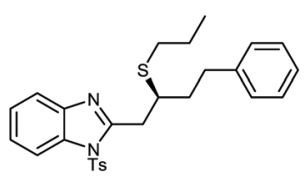

$17,90 \%$ yield, $96: 4$ er

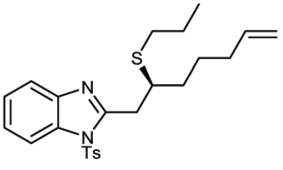

$18,77 \%$ yield, $94.5: 5.5$ er

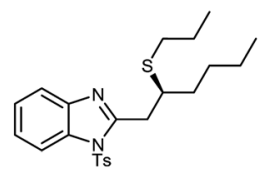

16, $83 \%$ yield, $93: 7$ er

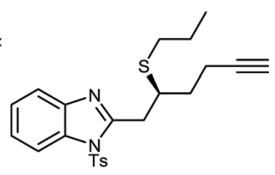

19, $80 \%$ yield, $96: 4$ er

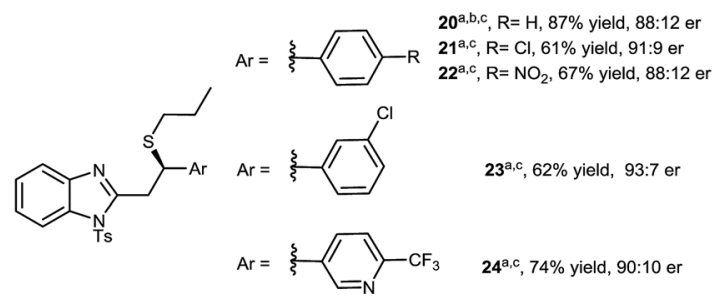

Scheme 2 Scope of the alkenyl benzimidazole coupling partner. ${ }^{\mathrm{a}}$ Reaction carried out at $22{ }^{\circ} \mathrm{C}$. ${ }^{\mathrm{b}}$ Reaction carried out using catalyst $\mathrm{F}$. ${ }^{\mathrm{c}}$ Reaction carried out in THF. ${ }^{\mathrm{d}}$ Reaction carried out using 3 eq. of thiol.

(15), however in these cases reactivity was found to diminish. This was easily circumvented by running the reaction at $22{ }^{\circ} \mathrm{C}$ using 3 equivalents of 1-propanethiol. ${ }^{18}$

Having varied the substitution pattern on the benzimidazole, we proceeded to investigate the scope with respect to substituents on the alkenyl moiety. The introduction of higher order linear alkyl chains, bearing aromatic, alkene and alkyne substituents, was well-tolerated with all $n$-propyl thiol Michael additions providing the corresponding products (16-19) in excellent yield and enantioselectivity. When substituting the alkene moiety with an aromatic group, the solvent was switched to THF and reactions were run at $22{ }^{\circ} \mathrm{C}$ due to decreased solubility and reactivity of the substrates. When a phenyl substituent was introduced on the alkenyl moiety, catalyst $\mathbf{G}$ only provided a moderate Michael adduct 20 in $77: 23$ er, however this was boosted to $88: 12$ when using diastereomeric catalyst F. Introducing electron withdrawing groups at either the para or meta positions of the phenyl ring afforded the corresponding products 21-23 in good yield and enantioselectivity; in these cases, however, catalyst $\mathbf{G}$ proved superior to F. Finally, when 


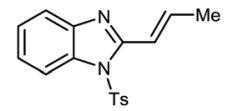

1

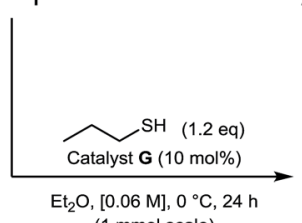
(1 mmol scale)

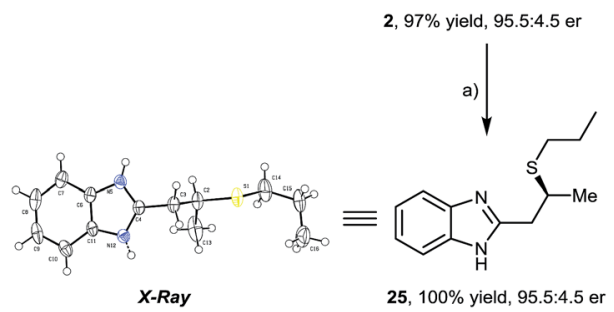

Scheme 3 Scale up (to $1 \mathrm{mmol}$ ) and derivatization of compound 2 and determination of absolute configuration of 25 by single crystal $\mathrm{X}$-ray analysis. (a) $5 \mathrm{M}$ aq. $\mathrm{HCl}, 40{ }^{\circ} \mathrm{C}$, THF, 10 h. (b) $\mathrm{m}$ - $\mathrm{CPBA}, \mathrm{CH}_{2} \mathrm{Cl}_{2}, 22^{\circ} \mathrm{C}$, $4 \mathrm{~h}$.

the phenyl ring was exchanged with a 3-pyridyl moiety, it smoothly afforded the corresponding adduct $\mathbf{2 4}$ in $74 \%$ yield and $90: 10 \mathrm{er}$.

Increasing the reaction scale 10 -fold $(1 \mathrm{mmol})$ afforded 2 in equal yield and er, which upon treatment with $\mathrm{HCl}$ (5 M aq.) gave corresponding deprotected product 25 in quantitative yield. Single crystal X-ray analysis of $\mathbf{2 5}$ allowed the absolute configuration of sulfa-Michael product 2 to be determined as $S$ when using catalyst $\mathbf{G}$. We were also pleased to find that, upon treatment of 2 with $m$-CPBA, sulfone 26 was obtained in $95 \%$ yield with no loss of optical purity (Scheme 3).

We used density functional theory (DFT) to investigate the origins of enantioselectivity, performing calculations at the
wB97XD/6-31G(d) level of theory (Fig. 3). ${ }^{19}$ Calculations considered $\mathrm{PPh}_{3}$-derived catalyst $\mathbf{G}^{*}$ with the $\mathrm{PMP}$-groups of $\mathbf{G}$ modelled by Ph-groups. The most stable conformation of (most enantioselective) catalyst $\mathbf{G}^{*}$ has substituents either side of the urea oriented with a hydrogen atom towards sulfur: other rotamers are disfavoured. This creates a pocket with the iminophosphorane positioned above the thiourea (from the perspective of Fig. 3). Two substrate activation modes are possible (A vs. B) and either could in principle lead to the formation of the major observed enantiomer. Computationally, we find that the interaction of the thiolate nucleophile with the protonated iminophoshorane and the benzimidazole with the thiourea (mode A) is energetically favored by 4$5 \mathrm{kcal} \mathrm{mol}{ }^{-1}$ over the alternative (mode B) in which the thiourea binds the nucleophile and the benzimidazole to the protonated iminophoshorane. This mode of activation is consistent with the observed sense of enantioselectivity, and with earlier mechanistic proposals of Takemoto. Recent theoretical studies of Grayson and Houk have emphasized the importance of activation mode $\mathrm{B}$ in sulfa-Michael reactions promoted by Cinchona-derived catalysts. ${ }^{20}$ Our present results suggest that both activation modes may be operative, depending on catalyst and substrate, as originally hypothesized by Soós and I. Pápai. ${ }^{21}$

\section{Conclusions}

In summary, the first enantioselective sulfa-Michael addition of alkyl thiols to alkenyl benzimidazoles has been described. Excellent yields and good enantioselectivities were achieved across a broad range of alkyl thiol and alkenyl benzimidazole reaction partners using a second generation BIMP organocatalyst. This work further demonstrates the versatility and high activity of the BIMP catalyst family, as well as expanding its use in methodology for the synthesis of biologically relevant chiral benzimidazole derivatives. Further investigations into new

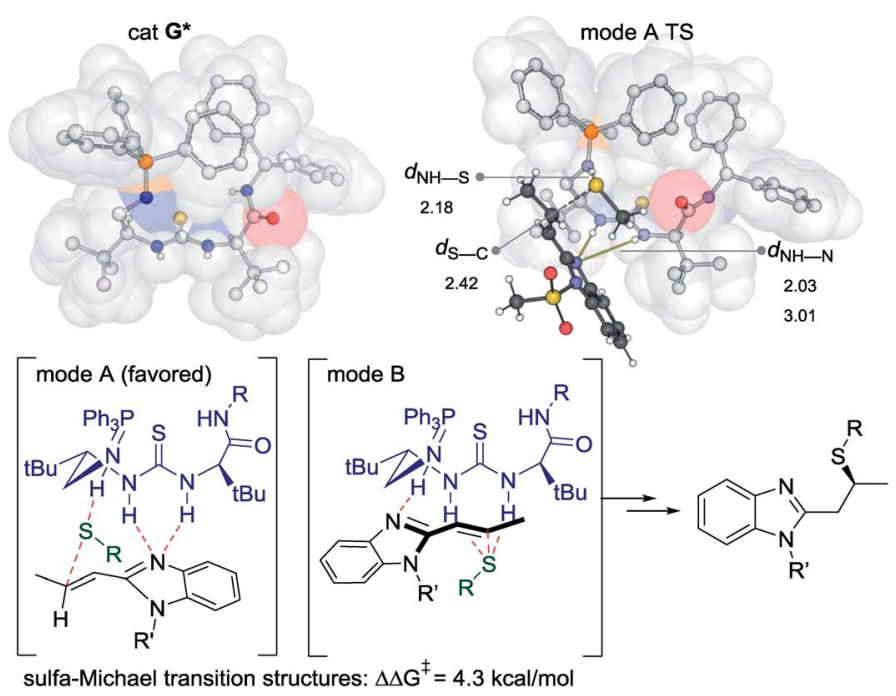

Fig. 3 SMD-wB97XD/6-31G(d) computed structure of catalyst $G *$ and the most favourable transition structure leading to the major enantiomer. 
catalyst designs and applications for BIMP promoted reactivity are underway in our laboratories.

\section{Conflicts of interest}

There are no conflicts to declare.

\section{Acknowledgements}

M. F. is grateful to the EPSRC Centre for Doctoral Training in Synthesis for Biology and Medicine (EP/L015838/1) for a studentship, generously supported by AstraZeneca, Diamond Light Source, Defence Science and Technology Laboratory, Evotec, GlaxoSmithKline, Janssen, Novartis, Pfizer, Syngenta, Takeda, UCB and Vertex. G. S. is grateful to the Université Paris Descartes for CRCT funding. J. D. thanks the Spanish Ministry of Education, Culture and Sports for a Jose Castillejo grant. We also thank Heyao Shi for X-ray structure determination and Dr Amber L. Thompson and Dr Kirsten E. Christensen (Oxford Chemical Crystallography Service) for X-ray mentoring and help. R. S. P. acknowledges the RMACC Summit supercomputer supported by the National Science Foundation (ACI-1532235 and ACI-1532236), the University of Colorado Boulder and Colorado State University and the Extreme Science and Engineering Discovery Environment (XSEDE) through allocation TGCHE180006.

\section{Notes and references}

1 For reviews on conjugate addition to N-containing heterocycles, see: (a) D. A. Klumpp, Synlett, 2012, 23, 1590; (b) D. Best and H. W. Lam, J. Org. Chem., 2014, 79, 831.

2 (a) L. Rupnicki, A. Saxena and H. W. Lam, J. Am. Chem. Soc., 2009, 131, 10386; (b) G. Pattison, G. Piraux and H. W. Lam, J. Am. Chem. Soc., 2010, 132, 14373; (c) A. Saxena and H. W. Lam, Chem. Sci., 2011, 2, 2326; (d) A. A. Friedman, J. Panteleev, J. Tsoung, V. Huynh and M. Lautens, Angew. Chem., Int. Ed., 2013, 52, 9755; (e) S. Wang, X. Li, H. Liu, L. Xu, J. Zhuang, J. Li, H. Li and W. Wang, J. Am. Chem. Soc., 2015, 137, 2303.

3 (a) R. P. Jumde, F. Lanza, M. J. Veenstra and S. R. Harutyunyan, Science, 2016, 352, 433; (b) R. P. Jumde, F. Lanza, T. Pellegrini and S. R. Harutyunyan, Nat. Commun., 2017, 8, 2058.

4 Y. Y. Wang, K. Kanomata, T. Korenaga and M. Terada, Angew. Chem., Int. Ed., 2016, 55, 927.

5 L. Wen, Z. Yue, H. Zhang, Q. Chong and F. Meng, Org. Lett., 2017, 19, 6610.

6 For reports on bifunctional iminophosphorane catalysis, see: (a) M. G. Núñez, A. J. M. Farley and D. J. Dixon, J. Am. Chem. Soc., 2013, 135, 16348; (b) A. M. Goldys, M. G. Núñez and D. J. Dixon, Org. Lett., 2014, 16, 6294; (c) A. J. M. Farley, C. Sandford and D. J. Dixon, J. Am. Chem. Soc., 2015, 137, 15992; (d) G. P. Robertson, A. J. M. Farley and D. J. Dixon, Synlett, 2016, 27, 21; (e) M. A. Horwitz, B. P. Zavesky, J. I. Martinez-Alvarado and J. S. Johnson, Org. Lett., 2016, 18, 36; (f) M. A. Horwitz, J. L. Fulton and
J. S. Johnson, Org. Lett., 2017, 19, 5783; $(g)$ J. Yang, A. J. M. Farley and D. J. Dixon, Chem. Sci., 2017, 8, 606; $(h)$ H. Shi, I. M. Michaelides, B. Darses, P. Jakubec, Q. N. N. Nguyen, R. S. Paton and D. J. Dixon, J. Am. Chem. Soc., 2017, 139, 17755; (i) J. L. Fulton, M. A. Horwitz, E. L. Bruske and J. S. Johnson, J. Org. Chem., 2018, 83, 3385. 7 For selected reviews on (thio)urea bifunctional organocatalysis, see: (a) Y. Takemoto, Org. Biomol. Chem., 2005, 3, 4299; (b) S. J. Connon, Chem. Commun., 2008, 0, 2499; (c) X. Yu and W. Wang, Chem.-Asian J., 2008, 3, 516; (d) F. E. Held and S. B. Tsogoeva, Catal. Sci. Technol., 2016, $6,645$.

8 For reviews on the use of organic superbases in organic synthesis, see: (a) C. Palomo, M. Oiarbide and R. López, Chem. Soc. Rev., 2009, 38, 632; (b) T. Ishikawa, Superbases for Organic Synthesis, John Wiley \& Sons, Ltd, Chichester, UK, 2009; (c) D. Leow and C. H. Tan, Chem.-Asian J., 2009, 4, 488; (d) D. Leow and C. H. Tan, Synlett, 2010, 11, 1589; (e) T. Ishikawa, Chem. Pharm. Bull., 2010, 58, 1555; (f) X. Fu and C. H. Tan, Chem. Commun., 2011, 47, 8210; $(g)$ T. Ishikawa and L. M. Harwood, Synlett, 2013, 24, 2507; $(h)$ H. Krawczyk, M. Dzięgielewski, D. Deredas, A. Albrecht and Ł. Albrecht, Chem.-Eur. J., 2015, 21, 10268; (i) B. Teng, W. C. Lim and C. H. Tan, Synlett, 2017, 28, 1272, for selected recent publications, see: (j) J. S. Bandar and T. H. Lambert, J. Am. Chem. Soc., 2013, 135, 11799; $(k)$ X. Gao, J. Han and L. Wang, Org. Lett., 2015, 17, 4596; $(l)$ M. Işk, M. Y. Unver and C. Tanyeli, J. Org. Chem., 2015, 80, 828; $(m)$ D. Uraguchi, K. Yamada and T. Ooi, Angew. Chem., Int. Ed., 2015, 54, 9954; (n) J. S. Bandar, A. Barthelme, A. Y. Mazori and T. H. Lambert, Chem. Sci., 2015, 6, 1537; (o) E. D. Nacsa and T. H. Lambert, J. Am. Chem. Soc., 2015, 137, 10246; ( $p$ ) M. A. Horwitz, N. Tanaka, T. Yokosaka, D. Uraguchi, J. S. Johnson and T. Ooi, Chem. Sci., 2015, 6, 6086; (q) A. Kondoh, M. Oishi, T. Takeda and M. Terada, Angew. Chem., Int. Ed., 2015, 54, 15836; (r) V. H. Lauridsen, L. Ibsen, J. Blom and K. A. Jørgensen, Chem.-Eur. J., 2016, 22, 3259; $(s)$ T. Takeda, A. Kondoh and M. Terada, Angew. Chem., Int. Ed., 2016, 55, 4734; $(t)$ D. Uraguchi, K. Yoshioka and T. Ooi, Nat. Commun., 2017, 8, 14793; (u) K. Yoshioka, K. Yamada, D. Uraguchi and T. Ooi, Chem. Commun., 2017, 53, 5495; (v) N. Tanaka, R. Tsutsumi, D. Uraguchi and T. Ooi, Chem. Commun., 2017, 53, 6999; (w) D. Uraguchi, R. Shibazaki, N. Tanaka, K. Yamada, K. Yoshioka and T. Ooi, Angew. Chem., Int. Ed., 2018, 57, 4732; (x) D. Uraguchi, Y. Kawai, H. Sasaki, K. Yamada and T. Ooi, Chem. Lett., 2018, 47, 594; (y) A. Kondoh, S. Akahira, M. Oishi and M. Terada, Angew. Chem., Int. Ed., 2018, 57, 6299; (z) D. Uraguchi, K. Yamada, M. Sato and T. Ooi, J. Am. Chem. Soc., 2018, 140, 5110.

9 For review on asymmetric sulfa-Michael additions, see: $(a)$ D. Enders, K. Luttgen and A. A. Narine, Synthesis, 2007, 959. For selected examples using metals, see: (b) K. Nishimura, M. Ono, Y. Nagaoka and K. J. Tomioka, J. Am. Chem. Soc., 1997, 119, 12974; (c) S. Kanemasa, Y. Oderaotoshi and E. Wada, J. Am. Chem. Soc., 1999, 121, 8675; (d) K. Nishimura, M. Ono, Y. Nagaoka and 
K. Tomioka, Angew. Chem., Int. Ed., 2001, 40, 440; (e) Y. Hui, J. Jiang, W. Wang, W. Chen, Y. Cai, L. Lin, X. Liu and X. Feng, Angew. Chem., Int. Ed., 2010, 49, 4290; (f) S. Bonollo, D. Lanari, F. Pizzo and L. Vaccaro, Org. Lett., 2011, 13, 2150; $(g)$ T. Kitanosono, M. Sakai, M. Ueno and S. Kobayashi, Org. Biomol. Chem., 2012, 10, 7134; $(h)$ T. Ogawa, N. Kumagai and M. Shibasaki, Angew. Chem., Int. Ed., 2012, 51, 8551.

10 For a review on organocatalytic asymmetric sulfa Michael addition reactions, see: (a) P. Chauhan, S. Mahajan and D. Enders, Chem. Rev., 2014, 114, 8807, for seminal contributions, see: (b) H. Hiemstra and H. Wynberg, J. Am. Chem. Soc., 1981, 103, 417; (c) A. Kumar, R. V. Salunkhe, R. A. Rane and S. Y. Dike, J. Chem. Soc., Chem. Commun., 1991, 485, for selected recent examples, see: (d) C. Palacio and S. Connon, Chem. Commun., 2012, 48, 2849; (e) D. Uraguchi, N. Kinoshita, D. Nakashima and T. Ooi, Chem. Sci., 2012, 3, 3161; (f) L. Dai, H. Yang, J. Niu and F. Chen, Synlett, 2012, 314; $(g)$ A. C. Breman, J. M. M. Smits, R. de Gelder, J. H. van Maarseveen, S. Ingemann and H. Hiemstra, Synlett, 2012, 23, 2195; $(h)$ X. Fang, J. Li and C.-J. Wang, Org. Lett., 2013, 15, 3448; $(i)$ R. A. Unhale, N. K. Rana and V. K. Singh, Tetrahedron Lett., 2013, 54, 1911; (j) R. Wang, J. Liu and J. Xu, Adv. Synth. Catal., 2014, 357, 159; (k) J. P. Phelan, E. J. Patel and J. A. Ellman, Angew. Chem., Int. Ed., 2014, 53, 11329; (l) N. K. Fu, L. Zhang, S. Z. Luo and J. P. Cheng, Org. Lett., 2014, 16, 4626; $(m)$ P. Yuan, S. Meng, J. Chen and Y. Huang, Synlett, 2016, 27, 1068; $(n)$ G. Wang, Y. Tang, Y. Zhang, X. Liu, L. Lin and X. Feng, Chem.-Eur. J., 2017, 23, 554; (o) Q. Wei, W. Hou, N. Liao and Y. Peng, Adv. Synth. Catal., 2017, 359, 2364; (p) A. Bacsó, M. Szigeti, S. Varga and T. Soós, Synthesis, 2017, 49, 429; (q) J. Guo and M. W. Wong, J. Org. Chem., 2017, 82, 4362; (r) A. K. Simlandy and S. Mukherjee, J. Org. Chem., 2017, 82, 4851; $(s)$ Y. Fukata, K. Yao, R. Miyaji, K. Asano and S. Matsubara, J. Org. Chem., 2017, 82, 12655; $(t)$ D. Hasılcıoğulları and C. Tanyeli, Tetrahedron Lett., 2018, 59, 1414.

11 For selected reviews on benzimidazoles in medicinal chemistry, see: (a) Y. Bansal and O. Silakari, Bioorg. Med. Chem., 2012, 20, 6208; (b) M. Gaba, S. Singh and C. Mohan, Eur. J. Med. Chem., 2014, 76, 494; (c) R. S. Keri, A. Hiremathad, S. Budagumpi and B. M. Nagaraja, Chem. Biol. Drug Des., 2015, 86, 19; (d) O. O. Ajani, D. V. Aderohunmu, C. O. Ikpo, A. E. Adedapo and I. O. Olanrewaju, Arch. Pharm. Chem. Life Sci., 2016, 349, 475; (e) P. M. Krishna Prasad, S. A. Kanvinde and S. Raja, Int. J. Pharm. Pharm. Sci., 2016, 8, 22.

12 Only one report describes the addition of thiols to alkenyl benzimidazoles promoted by $\mathrm{AcOH}$ at $100{ }^{\circ} \mathrm{C}$ to give racemic products: P. Dhanalakshmi and S. Shanmugam, Tetrahedron, 2015, 71, 6300.
13 The background reaction was found to be catalysed by trace amounts of acid present in the commercial 1-propane thiol; this however was not found to affect the BIMP catalysed reaction under the optimised conditions. Full control experiments are available in the ESI. $\dagger$

14 Catalyst $\mathbf{A}$ gave no conversion when the reaction was carried out at $0{ }^{\circ} \mathrm{C}$, using $1.2 \mathrm{eq}$. of thiol and $0.06 \mathrm{M}$ concentration for $24 \mathrm{~h}$.

15 Michael adduct 10 was deprotected to obtain free thiol 27 upon treatment with anisole in TFA at $65{ }^{\circ} \mathrm{C}$ without any loss of optical purity (see ESI $\dagger$ ).

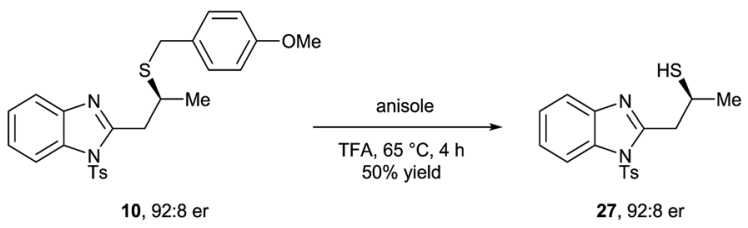

16 When 4-methylbenzene thiol was used as the nucleophile, the corresponding Michael adduct was obtained in $85 \%$ yield but only $69: 31$ er.

17 When the benzimidazole ring was substituted with a methyl group at the 4-position (28) the sulfa-Michael reaction failed to proceed under the optimised reaction conditions. When the reaction was run at $0.125 \mathrm{M}$ concentration in THF, $22{ }^{\circ} \mathrm{C}$ and with 3 equivalents of $n$-propane thiol, the corresponding sulfa-Michael product 29 was obtained in $60 \%$ yield and $50: 50$ er. See ESI $\dagger$ for full details.

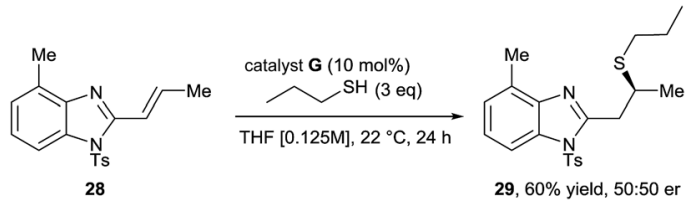

18 The sulfa-Michael reaction failed to proceed under the optimised reaction conditions when using the unprotected variant of benzimidazole 2 . When the reaction was run at $0.5 \mathrm{M}$ concentration, $22{ }^{\circ} \mathrm{C}$ and with 3 equivalents of $n$ propane thiol, 25 was obtained in $61 \%$ yield and $53: 47 \mathrm{er}$.

19 Calculations were performed with Gaussian 09 rev. D.01: Frisch, M. J. et al. Gaussian, Inc.: Wallingford, CT, 2013. All calculations were performed with an SMD model of diethyl ether. Full details are given in the ESI. $\dagger$

20 (a) M. N. Grayson and K. N. Houk, J. Am. Chem. Soc., 2016, 138, 1170; (b) M. N. Grayson and K. N. Houk, J. Am. Chem. Soc., 2016, 138, 9041; (c) M. N. Grayson, J. Org. Chem., 2017, 82, 4396.

21 A. Hamza, G. Schubert, T. Soós and I. Pápai, J. Am. Chem. Soc., 2006, 128, 13151. 